data. This needs to be investigated further because some of this information is important to assess issues of equity of access to bereavement services. Future work should define the minimum dataset of information which should be routinely collected by hospices.

\section{INVOLVEMENT IN PALLIATIVE AND END OF LIFE CARE RESEARCH}

${ }^{1}$ Elspeth Mathie, ${ }^{1}$ Julia Jones, ${ }^{2}$ Lorna Jacobs, ${ }^{3}$ Graham Rhodes, ${ }^{4}$ Catherine Harvey, ${ }^{4}$ Sanjay Thakrar. ${ }^{1}$ University of Hertfordshire, UK; ${ }^{2}$ CLAHRC East of UK; ${ }^{3}$ Patient and Public Involvement Panel, UK; ${ }^{4}$ Marie Curie, UK

\subsection{6/spcare-2019-mariecuriepalliativecare.25}

Involvement of those with experience of using care services is now an important and mandatory part of health and social care research, including palliative and end of life care. Those with direct experience of using palliative and end of life care (patients, carers, friends or family members), such as hospices and care homes can enhance and shape research (Goodman et al., 2011). The distinction is made between 'participants' in studies who provide 'data' and research carried out 'with' or 'by' members of the public (as defined by INVOLVE). Involvement in these research areas, has its own challenges (Backhouse et al., 2016; Mockford et al., 2016) and innovative approaches are needed (Brighton et al., 2018).

Seeking involvement from people with experience of care at an early stage of research development is key to ensure the research is user-friendly, feasible and has relevant outcomes. Three organisations ran a joint workshop focussing on palliative and end of life care to enable researchers to receive face to face comments from people with experience of palliative and end of life care on their research projects in a 'dragon's den' style session. We will share 1) our experience of this approach to involvement, 2) the experiences of the people who took part and 3) findings from the post evaluation. We will also outline the challenges of involving people in this research area, the importance of 'feedback' to those taking part (Mathie et al, 2018) and our learning for the future.

\section{PRESENT ABSENTEES: TREATMENT ESCALATION PLANNING}

Paulette Kumi, Myrna Scott, Deborah Dawson. St. George's Hospital, UK

\subsection{6/spcare-2019-mariecuriepalliativecare.26}

Introduction Escalation planning and resuscitation decisionmaking is essential for effective patient management. Treatment escalation plan (TEP) provides an effective way of formalising timely decision-making regarding care and communicating ceilings of care. It is more holistic - clarifying a wider remit of treatment options than DNACPR offers (Lipar, T., 2013). This is especially important in cardiothoracic intensive care (CTICU) where CPR has an even lower success rate due to the particular patient population and co-morbidities usually present (Barclay, S. et al., 2011).

Method A retrospective notes review was undertaken of patients admitted to St. George's CTICU from April - June 2019. The aims were to assess;
- Adequacy of End of Life Care (EoLC): recognition of dying, care planning, and provision of formalised anticipatory measures.

- whether Supportive and Palliative Care Indicators Tool (SPICT) and 'frailty' could have identified patients at risk of deteriorating health.

Result Of 107 patients sampled, less than 5\% had TEP preadmission. However, more than $80 \%$ required TEP on admission to ICU - with over $90 \%$ lacking capacity. SPICT identified $100 \%$ of patient requiring TEP while 'frailty' showed a lower percentage.

Discussion The above indicates that clinicians are missing the window where patients themselves can be involved in TEP discussions. The high percentage requiring TEP may also be indicative of the need for in-depth discussions around intensive palliative care, as awareness is raised about TEP.

Conclusion This study looks at the adequacy of EoLC and highlights the relevance of TEP form completion - especially at the ward level, where patients are more likely to have capacity. It also highlights the usefulness of SPICT and even stand-alone frailty in assessment of patient.

\section{AN ADEQUATE ETHICAL BASIS FOR PALLIATIVE CARE PROVISION}

Madeleine Fisher, Anshuni Kaneria, Wing May Kong. Faculty of Medicine Imperial College London, UK

\subsection{6/spcare-2019-mariecuriepalliativecare.27}

Currently, in England, palliative care provision could be argued to be unjust as it treats equals in need unequally. For example, those from black and ethnic minority groups (Public Health England, 2018), or those from a lower socioeconomic class (Macmillan, 2017), are much less likely to receive access to palliative care services. This paper sought an ethical framework that would adequately resolve this current injustice. An adequate ethical basis of palliative care would ensure a minimum baseline of care to all equals in need, without compromising palliative care's aims. This paper argues that this can be provided by using a care ethics framework in conjunction with justice.

Care ethics argues that caring and being cared for is universal and intrinsic to humanity (Tronto, 1993). A framework of care ethics could encourage all individual caregivers to provide the deeply holistic, individualised care currently provided in hospices. However, providing palliative care only from a care ethics perspective may mean that some go without care, as caring under this framework is voluntary, with no obligation to meet everybody's needs. Additionally, this may allow for the charitable basis of hospice funding to mask an unjust system, thus preventing social reform of palliative care services.

This paper argues that all should have equal access to highly individualised and holistic palliative care, as is currently provided in many hospices. An adequate ethical basis of palliative care provision would support this and would require both justice at the societal level and care ethics at the individual level. 